\title{
LENDAS AMAZÔNICAS EM POP-UP Desenvolvimento de ilustrações de lendas amazônicas aplicadas a estruturas de origami arquitetônico e mecanismos pop-up de um livro infanto-juvenil.
}

\author{
Sarah Batista Correa, UFAM \\ Helder Alexandre Amorim Pereira, UFAM
}

\begin{abstract}
Resumo: Este artigo trata do processo de desenvolvimento de ilustrações de lendas amazônicas aplicadas a estruturas de origami arquitetônico e mecanismos de interação . A metodologia utilizada foi a de Lobach (2010), com definição do problema, levantamento bibliográfico, análise de similares, aplicacão de questionário, definição de requisitos e parametros projetuais, a fim de que estes servissem de base para a geração e desenvolvimento de alternativas. Ao fim deste processo obteve-se como resultado um livro lúdico voltado para o público infanto-juvenil, contendo três lendas amazônicas ilustradas com o auxilio de estruturas pop-up e mecanismos de interação. Tais recursos não só encantam e divertem, como também informam o jovem leitor e incentivam a valorização da cultura amazônica.
\end{abstract}

Palavras-chave: Ilustração, Design Gráfico, Origami Arquitetônico, Folclore.

\begin{abstract}
This article describes the development of graphics Amazonian legends applied to architectural origami structures and mechanisms of interaction process. The methodology used was the Lobach (2010), with problem definition, literature survey, similar analysis, questionnaires, requirements definition and projective parameters in order that they might serve as a basis for the generation and development of alternatives. After this process was obtained as a result a playful book facing the juvenile population, containing three Amazonian legends illustrated with the help of pop-up structures and mechanisms of interaction. These resources not only delight and entertain, but also inform the young reader and encourage appreciation of the Amazonian culture.
\end{abstract}

Keywords: Illustration, Graphic Design, Architectural Origami, Folklore.

\section{INTRODUÇÃO}

As lendas e mitos que são parte do nosso folclore, da nossa identidade cultural, da nossa vida. A possibilidade de registrar esses fatos folclóricos por meio da escrita são de extrema importância para a sobrevivência dos mesmo, bem como a 
transmissão destes aos membros mais novos da comunidade amazônica.

Como base nisso, este projeto foi desenvolvido com o objetivo de obter como resultado final um livro capaz de despertar o interesse de crianças e jovens pela sua cultura de origem, contendo ilustrações de lendas amazônicas aplicadas em mecanismos pop-up e estruturas de origami arquitetônico.

Tais ilustrações foram desenvolvidas levando em conta elementos que fazem parte da cultura amazônica e do seu povo, sendo eles as cores, formas, traços faciais e estrutura corporal, entre outros, de modo que o leito infanto-juvenil que entrar em contato com o livro seja capaz de perceber a ligação dos aspectos visuais aplicados com o ambiente que o cerca.

O uso de ilustrações tridimensionais e estruturadas confere ao livro a possibilidade de trabalhar a interação do leitor com a informação a ser transmitida de modo que crie-se um vinculo emocional que auxilia a fixação das informações transmitidas. Sendo assim, este passa a atuar também como um mecanismo de preservação dos perfis visuais da identidade cultural amazônica pelo fato destas estarem adaptadas de forma atrativa para o mercado.

\section{DESIGN DE LIVROS INFANTO-JUVENIS}

O design de livros ou, de modo mais abrangente, o design editorial, trata essencialmente de dar forma visual a conteúdos (ou ideias) a serem publicados. A respeito disso Samara (2001, p.13) diz que:

É possível atribuir qualquer forma visual a uma ideia. A tarefa do designer, em colaboração com o editor, é determinar qual será a melhor forma. (...) o papel do designer é examinar o conteúdo e começar a pensar em sua aparência e sensação, em relação às suas mensagens.

Segundo Galbreath in Lupton (2008), o projeto editorial de um livro tem como base de trabalho as páginas duplas, de modo que as páginas da esquerda são sempre pares e as da direita são sempre ímpares. Ao abrir um livro, somente a primeira e ultima página não seguem o padrão explicado.

O autor afirma ainda que, dependendo da preferencia do editor responsável e da necessidade no projeto, a primeira página pode conter a página de rosto, que traz somente o título do livro, ou frontispício, que trás o título e informações relacionadas ao autor, ilustrador, tradutor, entre outros. A ultima é chamada de cólofon, que contém informações sobre a tipografia da obra, design do livro, estabelecimento impressor, entre outros.

No projeto de um livro infanto-juvenil, certas questões técnicas não se fazem tão necessárias. Para Lupton (2008), por exemplo, a página de rosto é considerada um luxo, e para o projeto de um livro voltado para o publico infanto-juvenil e marcado pelo predomínio de ilustrações em pop-up, certas partes são realmente dispensáveis.

\section{ORIGAMI ARQUITETÔNICO}

Existem modalidades de origami que vão muito além das formas de animais ensinadas na escola e que podem ser usadas de diversas formas. A seguir, serão explanadas três modalidades de origami, focando nos origamis arquitetônicos por ser a modalidade utilizada no projeto de livros pop-up.

O Origami(Figura 1) é uma tradicional arte japonesa que consiste em 
confeccionar figuras através da dobra de um papel, inicialmente quadrado. Sua origem é desconhecida, mas segundo Ueno (2003), acredita-se que estes teriam surgido na China, juntamente com a invenção do papel, tendo sido levado e difundido no Japão posteriormente. Atualmente, é comum que sejam ensinadas algumas dobraduras na escola, pois este tem a possibilidade de atuar de forma lúdica no aprendizado e na educação. No campo do design, é muito usado no estudo de forma para desenvolvimento dos conceitos de diferentes produtos, além de servir como base para a confecção de cartões, pastas, embalagens e outros.

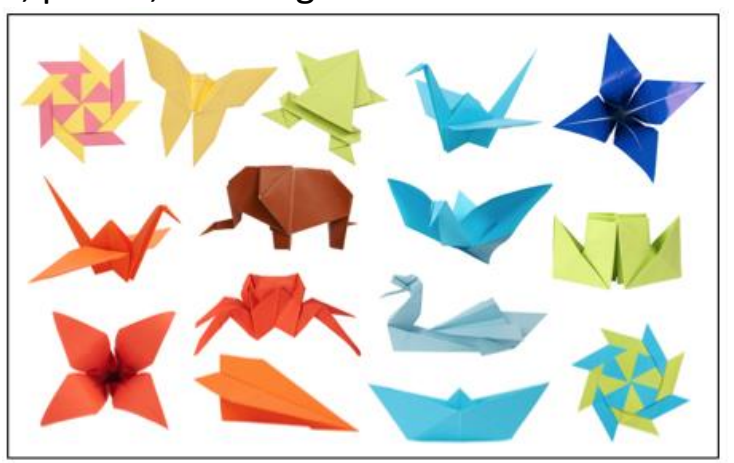

Figura 1 :

Exemplos

de

http://www.jccc.on.ca/en/programs/activities/origami.php

Fonte:

O Kirigami(Figura 2),que também é um tipo de arte com papel, diferente do origami, faz uso de técnicas de corte para conferir uma forma diferenciada ao material. Também sendo originário da China, este pode ser classificado de três formas:

- Senshi: é utilizada apenas a tesoura e a forma final é resultado de cortes feitos em uma figura dobrada sequencialmente.

- Sanshi: o papel é recortado manualmente e é mais usado por crianças.

- Kokushi: são utilizadas lâminas de estilete para o corte e o resultado final apresenta imagens positivas e negativas

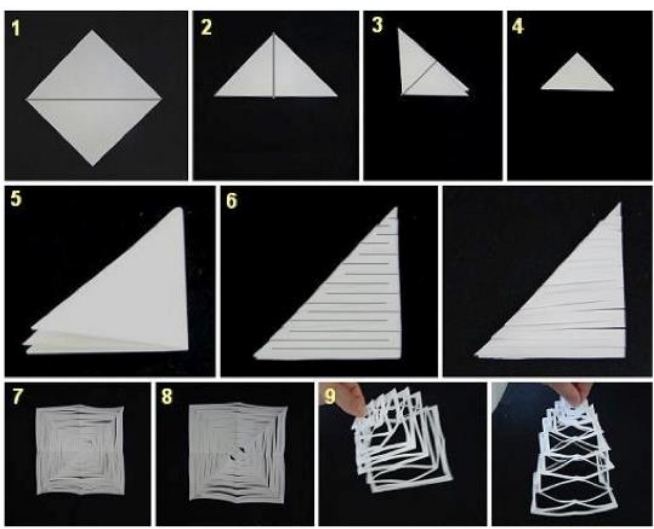

Figura 2: Proceso de realização de um kirigami. Fonte: http://www.origami-resourcecenter.com/hanging-kirigami-decoration.html

Por fim, Ueno (2003) aponta a existência do Origami Arquitetônico, também chamado de "Pop-up architecture", "3D Cards", "Kirigami tridimensional", entre outros. Ele é tido como uma evolução das modalidades anteriormente explicadas, devido ao uso da dobra (origami) e do corte (kirigami) para conferir características tridimensionais às figuras que antes eram bidimensionais.

Para chegar a esse resultado, é necessário um desenvolvimento longo, 
passando por vários testes, planificações e detalhamentos. Todo esse processo toma por base a geometria, que determina os parâmetros que vão viabilizar a projeção da imagem, tais como a distância entre os planos (quando houver) e a proporção de cada figura ou parte da figura projetada, as marcas de corte e dobra e suas distâncias da dobra central do cartão.(UENO, p.39)

Existem quatro modalidades de origami arquitetônico, que são classificadas de acordo com o angulo de abertura em que o cartão confere volume à figura, sendo elas:

- Origamis arquitetônicos de $90^{\circ}$ : são aqueles cujas figuras adquirem volume quando o cartão é aberto nesse angulo, como pode ser observado na figura 3 , e voltam à forma planificada quando o cartão é aberto em $180^{\circ}$. Esta é a modalidade mais difundida e aplicada.

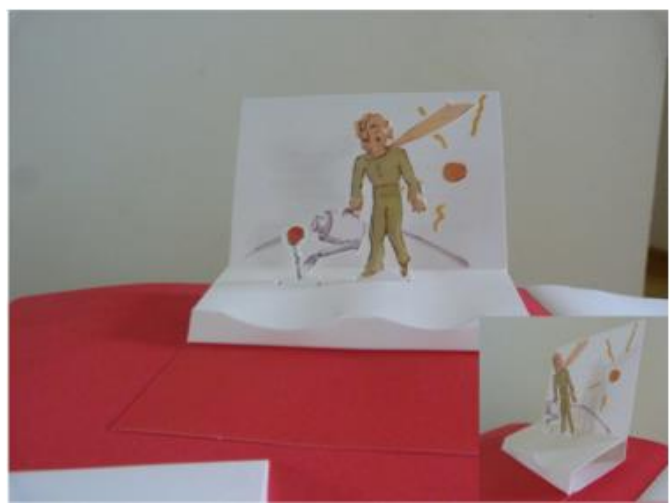

Figura 3: Origami arquitetonico de $90^{\circ}$ do livro "O Pequeno Príncipe". Fonte: Elaborado pelo autor, com base na pesquisa realizada

- Origamis arquitetônicos de $180^{\circ}$ (Figura 4): seguem o mesmo raciocínio dos explanados anteriormente, porém podem utilizar a junção de duas folhas de papel com "imagens simétricas espelhadas que, quando dobradas e montadas, dão o efeito tridimensional. Pode ocorrer também o entrelaçamento das imagens para que fiquem na posição vertical quando o cartão é aberto". (UENO, 2003, p. 47)

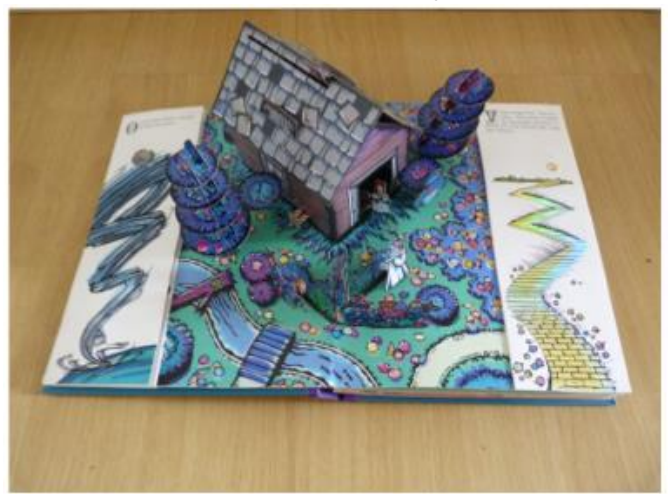

Figura 4: Origami arquitetonico de $180^{\circ}$ do livro "O Mágico de Oz". Fonte: Elaborado pelo autor, com base na pesquisa realizada

- Origamis arquitetônicos de $360^{\circ}$ : utilizam o mesmo princípio dos de $180^{\circ}$, porém a imagem deve apresentar sua forma final apenas quando o cartão é aberto em $360^{\circ}$, como pode ser observado na figura 5 . 


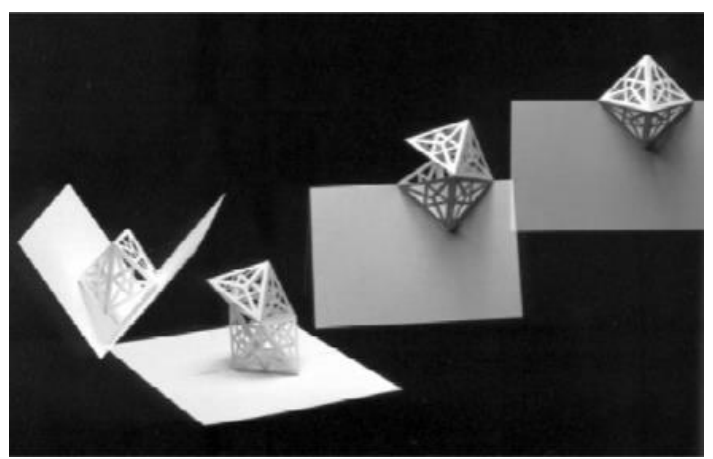

Figura 5: Abertura de um origami arquitetonico de $360^{\circ}$. Fonte: UENO, 2003.

- Origamis arquitetônicos de $0^{\circ}$ : a primeira vista podem parecer feitos a partir da junção de varias camadas de papel, quando na verdade são feitos a partir de uma única folha de papel, apresentando uma forma tridimensional antes mesmo de aberto.

\section{ASPECTOS CULTURAIS}

O estudo do conceito de identidade cultural se faz necessário a esse projeto para o entendimento adequado dos aspectos que serão utilizados como base para o desenvolvimento da ilustrações do livro. Para isso serão estudadas as partes formadoras deste conceito maior, a identidade, cultura e folclore.

\subsection{Identidade}

Identidade é um termo que pode ser aplicado em uma enorme diversidade de definições, assumindo as mais diferentes interpretações, estando presentes em uma crescente quantidade de estudos em campos que vão muito além do design.

Para Goytisolo apud Bonsiepe(2010), "a identidade nos é revelada como algo que precisa ser inventado e não apenas descoberto". Seguindo a lógica de Bonsiepe, é interessante para este projeto frisar que a identidade pode e deve ser projetada pelo design.

Levando tais afirmações ao projeto desenvolvido, pode-se concluir que a identidade deve ser levada em conta em todo o projeto gráfico de um livro, sendo aplicada desde a escolha da tipografia, passando pelo estilo da ilustração, design de superfície, escolha de materiais, cores e muito mais. Tudo isso se deve ao fato de que o livro não deverá apenas conter estruturas ou ser um grupo de folhas com palavras escritas, ele deve ter alma e personalidade.

\subsection{Cultura}

Segundo Tylor (1871), o termo cultura engloba "o conhecimento, as crenças, a arte, a moral, a lei, os costumes e todos os outros hábitos e aptidões adquiridos pelo homem como membro da sociedade."

Para Santaella (2003, p.31), "a cultura é a parte do ambiente que é feita pelo homem", de modo que nela estão inseridos desde os ritos religiosos, até modos de cultivar a terra ou simples ditos populares. Ou seja, todos os elementos que foram passados a um grupo humano, consciente ou inconscientemente, e tudo aquilo que torna a vida social simbólica pertence a cultura.

\subsection{Folclore}

Segundo Sanches (2012), a palavra folklore vem de folk-lore, que significa 
"coisa do povo" e definida como a reunião de fatos oriundos de costumes e tradições que não possuem data de origem ou autor conhecido, não possuindo também nenhuma fundamentação técnica. O autor ainda afirma que estes fatos encontram-se nos jogos infantis e cantigas de roda e religiosas, além de outros, podendo ser facilmente identificadas.

As chamadas "coisas do povo" surgiram da necessidade de encontrar uma explicação para fatos inexplicáveis, cuja fundamentação era proveniente do conhecimento proveniente da própria cultura mesclado aos conhecimentos transplantados através do contato com outra cultura.

É desse processo que nascem as lendas e mitos que relatam a ação de espíritos protetores das florestas, sereias sedutoras, sacis implicantes e bichos que viram gente e gente que vira bicho. Essas explicações acabavam por sofrer pequenas ou profundas variações, dependendo da realidade na qual estava inserida.

\subsection{Mitos e Lendas}

Desde a infância a vida do brasileiro é marcada pela presença de mitos e lendas, cujos significados acabam por gerar diversos efeitos nos diferentes grupos sociais em que se apresentam. Para entender esses efeitos é necessário saber diferenciar esses dois termos.

De acordo com Sanches (2012, p.199), mito é aquele ser acometido por acontecimentos fantástico, podendo ser o autor, a testemunha ou a vítima desses acontecimentos. É ele a parte encarnada dos fenômenos da natureza, o personagem principal das histórias que tem por objetivo dar sentido aos fatos comuns da vida de uma comunidade, funcionando como "mediador entre o sagrado e o profano.

Partindo para o entendimento do que são as lendas, Sanches (2012) afirma que estas se caracterizam pela "transformação da realidade, de forma exagerada ou colorida, ou ambas, que se vincula a um grupo social, ou mais amplamente a uma sociedade."

Dessa forma, percebe-se que as lendas são os acontecimentos fantásticos que permeiam os mitos. É a sequência de fatos que dão sentido aos acontecimentos que até então não possuíam explicação.

\section{METODOLOGIA}

As etapas projetuais adotadas para o desenvolvimento do projeto seguiram as estabelecidas por Löbach (2001), segundo o qual, o projeto de design pode ser dividido nas seguintes etapas: Análise do problema, Geração de alternativas, Avaliação de alternativas e realização de alternativas.

\subsection{Análise do Problema: O Design de Livros Pop-up}

Na etapa de análise do problema, foi definido como objeto de estudo o design de livros pop-up e partindo deste ponto procedeu-se o levantamento de dados por meios bibliográficos e por meio da aplicação de um questionário. Então, apartir da análise dos dados levantados, foi possível definir os requisitos e parâmetros projetuais.

Também fez parte desta etapa a análise morfológica, mercadológica e de interação de 3 livros pop-up de diferentes editoras como similares, onde procurou-se perceber os tipos de estrutura e a quantidade presente em cada livro, o tipo de encadernação, estilo de ilustração, diagramação, valores de venda e a presença de 
outros recursos de interação que visavam tonar o livro mais atrativo.

Com relação ao questionário, este foi aplicado online a 30 pessoas de 21 a 51 anos de idade que tivessem proximidade com crianças de 7 a 11 anos, podendo ser filhos, irmãos, primos, sobrinhos etc, com o objetivo de testar o interesse do publico pelo projeto e se estavam familiarizados com o tipo de livro que se pretendia projetar.

Ao serem questionados quanto ao hábito de presentear crianças pode-se perceber que $97 \%$ dos entrevistados afirmaram ter esse hábito, dentre os quais $53 \%$ afirmaram dar livros.

Buscou-se perceber também o interesse e o grau de contato que o público tinha com os livros pop-up. Revelou-se que $77 \%$ dos entrevistados já haviam tido a oportunidade de manusear um livro com arquitetura de papel e que $80 \%$ já tiveram vontade de comprar um livro pop-up. Outro ponto interessante é o de que $70 \%$ dos entrevistados afirmaram que comprariam um livro pop-up que contasse uma lenda amazônica.

Esses dados revelam que o desejo de incentivar o hábito da leitura em crianças ainda está bastante presente no mercado consumidor de produtos infanto-juvenis e que os livros pop-up conseguem encantar também os adultos.

Por fim, para saber quais lendas despertariam o desejo de compra no publico, foi apresentada uma lista com 11 opções, havendo ainda espaço para adição de novas, dentre as quais destacaram-se a Lenda da Vitória Régia, com 67\%, a Lenda do Boto, com 53\% e a Lenda da Cobra Grande, com 47\%. Esses dados então serviram para validar a utilização dessas três lendas para a elaboração do conteúdo escrito do livro.

\subsection{Geração e Avaliação de Alternativas}

A etapa de geração de alternativas foi procedida com base nos conceitos de sintaxe visual de Dondis (2007), sendo feita primeiramente a geração de prévias das ilustrações com base nos conceitos de simplicidade, espontaneidade e profusão. Esses conceitos foram apresentados a crianças de 7 a 11 anos para que fosse escolhido o que mais chamava atenção do público usuário. Tendo sido o conceito de profusão o que mais se adequou as preferências estéticas dos entrevistados, foram geradas três alternativas com base nele, cada uma contendo 3 personagens, 6 elementos naturais e uma ilustração com prévia de diagramação aplicada que podem ser observados na figura 5.

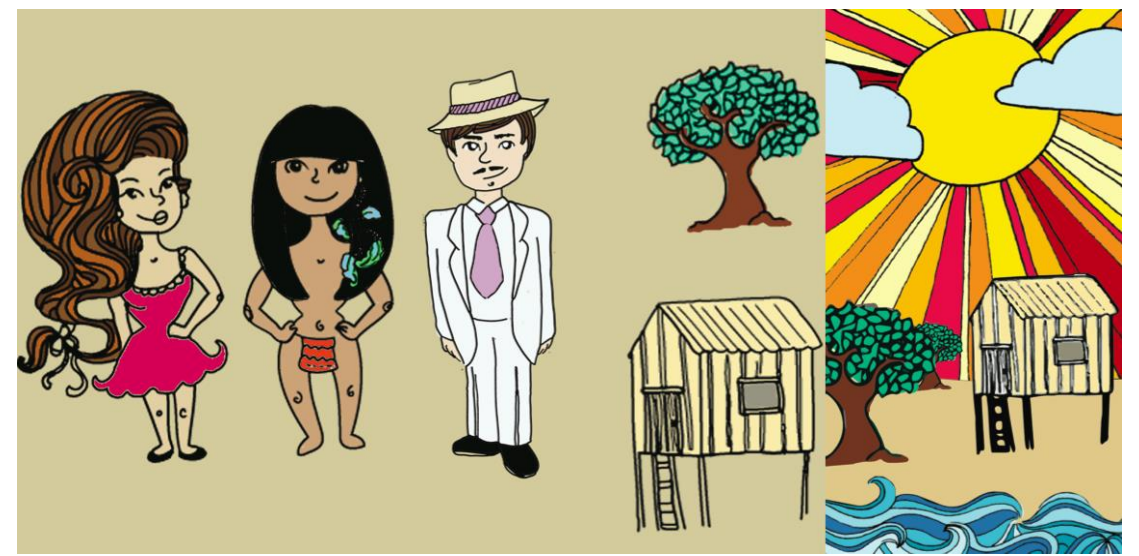

Figura 5: Ilustrações geradas com base no conceito de sintaxe visual de profusão. Fonte: Elaborado pelo autor, com base na pesquisa realizada 
Em seguida, as alternativas foram submetidas a uma matriz de seleção onde foram avaliadas quanto a clareza, limpeza visual, expressividade, atratividade/capacidade de chamar atenção e ritmo/movimento, podendo receber uma nota de 0 a 10 pontos. Para melhor avaliar as variáveis, foram analizados separadamente os personagens, os elementos naturais e a paisagem elaborada para a cena de uma das lendas e ao fim todas as pontuações foram somadas, concluindo assim a etapa de avaliação de alternativas.

\subsubsection{Testes de estruturas e mecanismos}

Sendo a alternativa I a que atingiu maior pontuação, passou-se então para a etapa de realização da alternativa selecionada. Como observou-se aspectos interessantes a serem mantidos na alternativa II, optou-se por mesclar aspectos desta para então seguir com o desenvolvimento de outros personagens e das ilustrações de cada lenda.

Com os personagens principais e alguns elementos naturais definidos, passouse então para o desenvolvimento das ilustrações de cada lenda, de acordo com a descrição dos acontecimentos presente em cada parágrafo de texto, já tendo em mente uma possível aplicação em estrutura pop-up. Neste momento definiu-se também a divisão igualitária da quantidade de páginas, de modo que cada lenda teria 4 páginas duplas, resultando em um total de 24 páginas ilustradas com estruturas e mecanismos pop-up.

Após desenvolvidas as ilustrações que serviram de base para o desenvolvimento do livro, fez-se necessário por em prova as estruturas, angulações e mecanismos comumente utilizados em livros desse segmento. Primeiro foram testadas as estruturas de $180^{\circ}$ de volume e levantamento afim de entender os efeitos que as mesmas sofriam de acordo com a mudança de ângulos usados para fixa-las na base.

Em seguida foram testados mecanismos mais complexos que envolveriam a interação do usuário. Um deles seria a movimentação da personagem indígena e do boto na forma animal, presentes nas ilustrações das páginas $7 / 8$ e $21 / 22$. Para que 0 que este funcionasse adequadamente, foi fixado um círculo vazado, por onde passa a tira de papel que fará o personagem se movimentar. Esse círculo se faz necessário para que a outra parte tenha um eixo de movimento, impedindo também que esta fique solta, subindo e descendo entre o corte.

Outro mecanismo de interação se refere a descrição das índias que viram estrelas, representado na ilustração da página 19/20. Para que a personagem indígena fosse levada para dentro da lua, surgindo depois como uma estrela, foi utilizado $1 / 4$ de um círculo, que foi encaixado em um furo no círculo que seria usado como base. Em cada uma das extremidades do $1 / 4$ de círculo foi fixado as imagem que seriam movimentadas (índia e estrela). Para que a movimentação fosse possível, foi feito outro corte nesse 1/4 de círculo, onde seria encaixado uma tira de papel que, ao ser puxada pra a baixo ou para cima, acionaria o mecanismo.

Por ultimo, foi testado o mecanismo de imagem dissolvente, onde uma imagem surge escondendo a mostrada anteriormente ao ser puxado. Para que isso ocorra, a imagem a ser revelada deve sofrer cortes paralelos, com cantos formando ângulos de $150^{\circ}$, enquanto a imagem que deverá cobrir a anterior deve sofrer cortes com um inclinação de $80^{\circ}$ e cantos formando um angulo de $130^{\circ}$ na direção oposta a primeira imagem, como pode ser visto na figura 6 . Então essas duas partes devem ter suas tiras 
encaixadas. Observou-se ainda a necessidade de fixação em um plano, para que o mecanismo corra adequadamente.

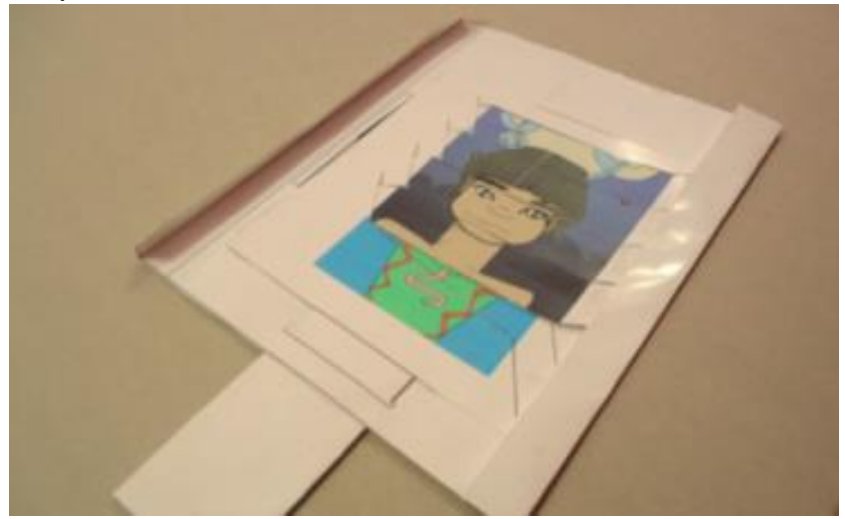

Figura 5: Mecanismo de imagem dissolvente para teste. Fonte: Elaborado pelo autor, com base na pesquisa realizada.

\subsubsection{Aplicação das ilustrações nas estruturas e mecanismos pop-up}

Após esses estudos e testes, cada uma das ilustrações sofreu alterações e foi aplicada a estruturas de origami arquitetônico. Para a lenda do boto foram geradas 6 estrutras, distribuídas em 4 páginas duplas. Na primeira foram aplicados os ângulos de $45^{\circ}$ para que as barraquinhas, bandeirinhas e fogueira pudessem ser erguidos e as figuras humanas erguidas com uma estrutura de fixação em V. Na segunda foram usadas estruturas de $90^{\circ}$ e um mecanismo de interação que faz os personagens se movimentarem. Na terceira o casal na canoa foi fixado na base novamente com um angulo de $45^{\circ}$ que possibilita o levantamento ao abrir a página. Na quarta foi utilizado o mecanismo de interação com um eixo circular, permitindo a movimentação do boto.

Para a lenda da cobra grande foram desenvolvidos outras 6 ilustrações a serem aplicadas em 4 páginas duplas. Na primeira foram utilizados mecanismos de volume, na segunda foram utilizados cartões de $180^{\circ}$, na terceira foi utilizado o mecanismo de imagem dissolvente e na ultima, o processo de quebra do feitiço foi mostrado através do uso de 2 cartões com estruturas de $90^{\circ}$.

Por fim, foram desenvolvidas 4 ilustrações referentes a lenda da vitória- régia, sendo estas distribuídas em outras 4 páginas duplas. Na primeira foram utilizados mecanismos de volume, na segunda foi utilizado o mecanismo de movimento, na terceira foi utilizado mecanismo com eixo circular para dar movimento a personagem e na quarta e ultima temos uma estrutura de $180^{\circ}$ para a flor da vitória-régia e para a personagem.

\subsubsection{Editorial, diagramação e tipografia}

Após desenvolvidas e testadas as estruturas de cada página, deu-se inicio ao processo de editoração do livro, diagramação do texto e escolha da tipografia de título e de texto.

Primeiramente foi escolhida a tipografia mais adequada para o texto das lendas. Dentre as usadas na geração de alternativa e optou-se por utilizar a Playtime With Hot Toodies regular em 21pt, pela sua legibilidade e características formais espontâneas e infantis, além do aspecto rústico presente na mesma. Para a tipografia de título foi escolhida a Flavors regular, pela pregnância, força e caráter rústico que se adequava ao projeto. Ambas famílias tipográficas podem ser observadas na figura 7. 
Tipografia para texto: Playtime With Hot Toodies

\section{$\mathrm{AaBbC} c \mathrm{DdEeFfGgHhliJjKkLIMmNn}$ OoPpQqRrSsTtUuVvWwXxYyZz 0123456789}

Tipografia para título: Flavors

\section{AaBbCCDdlefFGgHhliJjkkLIMmNn OOPPQGRPSSTtUUVWWWXXYYZz 0123456789}

Figura 7: Famílias tipográficas utilizadas no projeto do livro. Fonte: Elaborado pelo autor, com base na pesquisa realizada.

Em seguida foram inseridos os parágrafos diagramados de acordo com a localização em cada página. Nas páginas $6 / 7$ (figura 8), por exemplo, o parágrafo foi dividido em 2 partes, sendo estas inseridas nos cartões que continham as estruturas de $90^{\circ}$, ambos alinhados a esquerda. O mesmo foi feito nas páginas $16 / 17$ e 20/21.

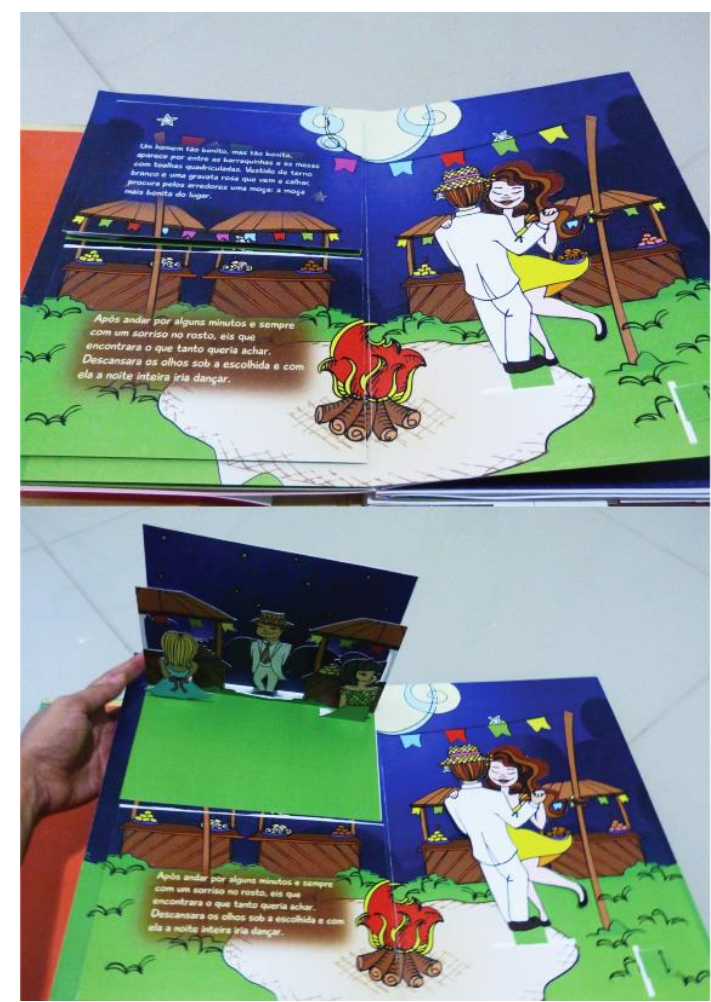

Figura 8: Diagramação de texto e estruturas de $90^{\circ}$ referentes a lenda "O Boto", localizadas nas páginas $6 / 7$.

Posteriormente foram feitos o frontispício, colofón, páginas de capítulo e ultima página que, junto com a contra-capa, auxiliam no acabamento da capa. Para o frontspício e colofon foram usados um laranja com as informações na tipografia Flavors regular na cor branca. Para as páginas de capitulo foram feitos padrões ligados a cada uma das histórias e o título das lendas foi colocado no centro da página, 
também na tipografia Flavors regular.

A capa ganhou uma ilustração onde estão presentes um elemento natural, a árvore, e os personagens principais das lendas contadas, a índia Naiá, o Boto e as cobras irmãs. O livro foi impresso em formato A3 e montado em papel chambril $240 \mathrm{~g} / \mathrm{m} 2$, a fim de conferir durabilidade as estruturas e mecanismos. A capa foi feita em papelão paraná $180 \mathrm{~g} / \mathrm{m} 2$ e coberta com uma capa em oficio $25 \mathrm{~g} / \mathrm{m} 2$

\section{RESULTADOS}

Ao fim do processo de montagem, obteve-se como resultado um livro pop-up em formato A4 de capa dura com 31 páginas, contendo as lendas amazônicas "O Boto", "Vitória-régia" e "Cobra Grande", contadas com o auxilio de mecanismos e estruturas de interação.

$\mathrm{Na}$ figura 9 pode ser observado a capa do livro e 3 estruturas de origami arquitetônico de $180^{\circ}$ referentes consecutivamente a lenda do boto, da cobra-grande e da vitória-régia. Na figura 10 temos 3 tipos de mecanismos de interação, sendo o primeiro e o último de movimentação a partir de eixo circular e o do meio do tipo imagem dissolvente. Mais uma vez cada um diz respeito a uma lenda.

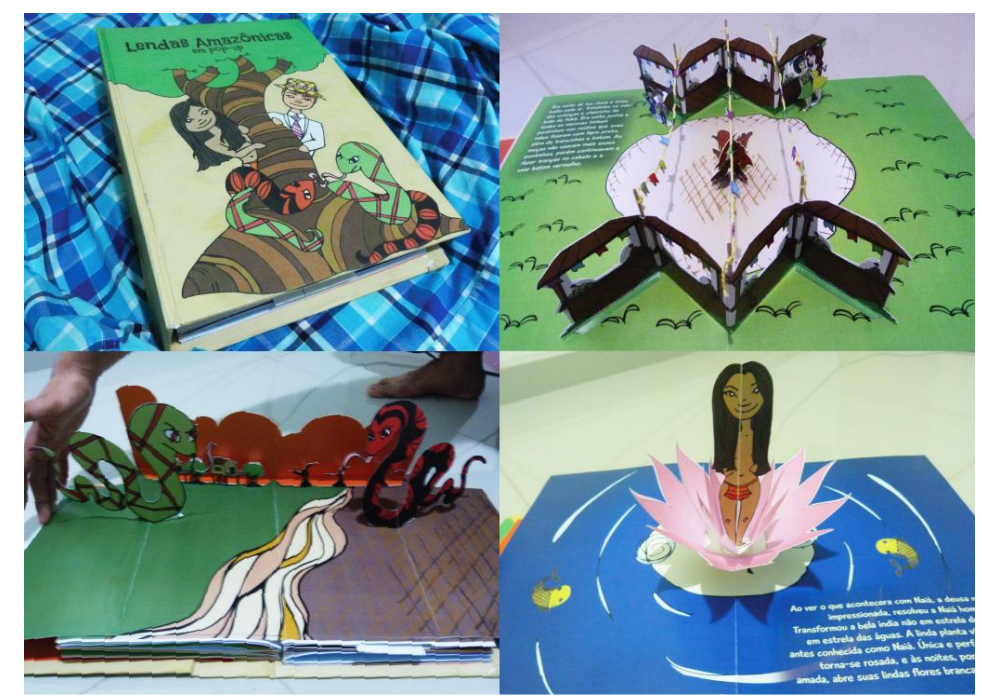

Figura 9: Capa e estruturas de origami arquitetônico presentes no livro referentes a lenda "O Boto", "Cobra Grande" e "Vitória-Régia”.

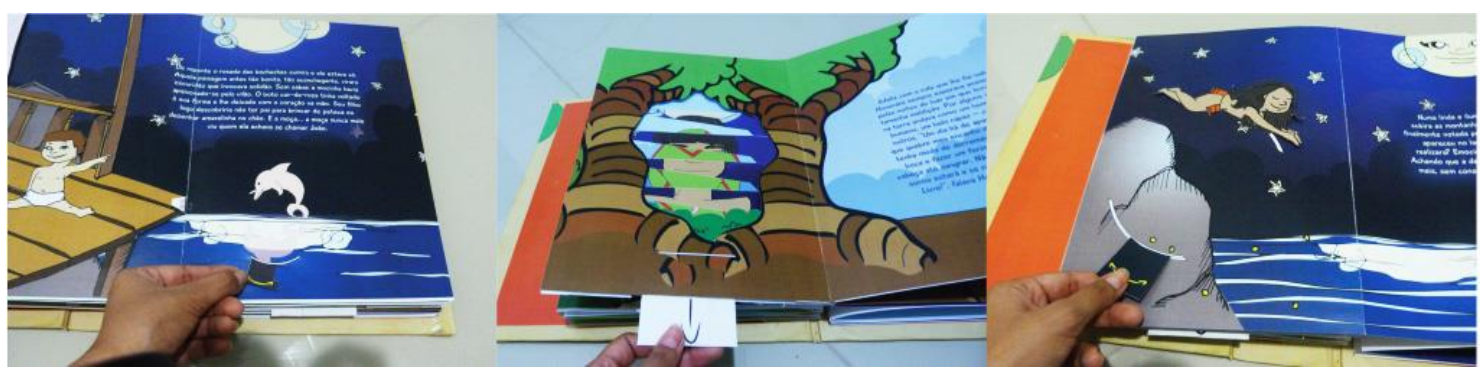

Figura 10: Mecanismos de interação presentes no livro referentes a lenda "O Boto", "Cobra Grande" e "Vitória-Régia".

\section{CONCLUSÃO}

O desenvolvimento deste projeto considerou não somente o projeto de um livro em si, mas também o levantamento de uma grande quantidade de informações que possibilitaram que o livro gerado tivesse uma base teórica sólida. Diante disso e do 
resultado obtido com o produto final, considerou-se satisfatório o desenvolvimento, por mais árduo que tenha sido.

A opção de usar estruturas de origami arquitetônico e mecanismos de interação gerou a necessidade de entender o funcionamento dos mesmos para que a adaptação as lendas contadas fosse possível de ser realizada. Os resultados obtidos e as possibilidades de aplicação as ilustrações, entretanto, sempre eram surpreendentes e acabaram por conferir ainda mais personalidade ao projeto do livro.

O processo de ilustração levou a um aperfeiçoamento dos conhecimentos que já se tinham antes do inicio deste projeto e o texto usado como base para o desenvolvimento revelou as possibilidades extraordinárias que os mitos e lendas amazônicas oferecem para um ilustrador. Sendo assim, espera-se que este projeto sirva de estimulo para que outros profissionais também busquem trabalhar com a aplicação de elementos do folclore e cultura amazônica aos diversos campos de atuação do design.

\section{REFERÊNCIAS}

BONSIEPE, Gui. Design, Cultura e Sociedade. São Paulo: Blucher, 2011.

BONFIM, Gustavo Amarante. Metodologia para Desenvolvimento de Projetos.João Pessoa: Editora Universitária UFPB, 1995.

DONDIS, Donis A. Sintaxe da Linguagem Visual. 3. Ed. Traduzido por Jefferson Luiz Camargo. São Paulo: Martins Fontes, 2007. Tradução de: A primer of visual literacy.

LÖBACH, Bernd. Design industrial: bases para a configuração dos produtos industriais. Tradução: Freddy Van Camp.1.ed.São Paulo: Editora Edgard Blücher Ltda. 2001

LUPTON, Ellen (org.). A produção de um livro independente - Indie Publishing: um guia para autores, artistas e designers. Traduzido por Maria Lúcia L. Rosa. São Paulo: Edições Rosari, 2011. Tradução de: Indie Publishing: How to design and produce your own book.

SAMARA, Timothy. Guia de design editorial: Manual prático para o design de publicações. Traduzido por Mariana Bandarra. Porto Alegre: Bookman, 2011. Tradução de: Publication Design Workbook: A real-World Design Guide.

SANCHES, Cleber. A cultura popular no Brasil. Manaus: Valer, 2012.

SANTAELLA, Lúcia. Culturas e artes do pós-humano: da cultura das mídias à cibercultura. São Paulo: Paulus, 2003.

UENO, THAIS REGINA. Do origami tradicional ao origami arquitetônico: uma tragétoria histórica e técnica do artesanato oriental em papel e suas aplicações no design contemporâneo. Bauru, 2003. Programa de pós- graduação em desenho industrial. Em UNIVERSIDADE ESTADUAL PAULISTA JULIO DE MESQUITA FILHO. 